\title{
Thyroid cancer risk in the Swedish AMORIS study: the role of inflammatory biomarkers in serum
}

\author{
Arunangshu Ghoshal ${ }^{1,9}$, Hans Garmo ${ }^{1,2}$, Rhonda Arthur ${ }^{1}$, Paul Carroll ${ }^{8}$, Lars \\ Holmberg ${ }^{1}$, Niklas Hammar ${ }^{3,4}$, Ingmar Jungner ${ }^{5}$, Håkan Malmström ${ }^{6,10}$, Mats \\ Lambe $^{2,6}$, Göran Walldius ${ }^{7}$ and Mieke Van Hemelrijck ${ }^{1,3}$ \\ ${ }^{1}$ King's College London, School of Cancer and Pharmaceutical Sciences, Translational Oncology and Urology Research, \\ London, UK \\ ${ }^{2}$ Regional Cancer Centre, Uppsala University, Uppsala, Sweden \\ ${ }^{3}$ Unit of Epidemiology, Institute of Environmental Medicine, Karolinska Institutet, Stockholm, Sweden \\ ${ }^{4}$ AstraZeneca R\&D, Mölndal, Sweden \\ ${ }^{5}$ Department of Medicine, Clinical Epidemiological Unit, Karolinska Institutet and CALAB Research, Stockholm, Sweden \\ ${ }^{6}$ Department of Medical Epidemiology and Biostatistics, Karolinska Institutet, Stockholm, Sweden \\ ${ }^{7}$ Unit of Cardiovascular Epidemiology, Institute of Environmental Medicine, Karolinska Institutet, Stockholm, Sweden \\ ${ }^{8}$ Endocrinology Department, Guy's and St Thomas' NHS Foundation Trust, London, UK \\ ${ }^{9}$ Department of Palliative Medicine, Tata Memorial Hospital, Mumbai, India \\ ${ }^{10}$ Biostatistics, Research \& Development, Swedish Orphan Biovitrum AB, Stockholm, Sweden
}

Correspondence to: Arunangshu Ghoshal, email: arung@kcl.ac.uk

Keywords: albumin; AMORIS cohort; cox analysis; serum inflammatory markers; thyroid cancer

Received: July 25, 2017 Accepted: November 07, $2017 \quad$ Published: December 04, 2017

Copyright: Ghoshal et al. This is an open-access article distributed under the terms of the Creative Commons Attribution License 3.0 (CC $\mathrm{BY}$ 3.0), which permits unrestricted use, distribution, and reproduction in any medium, provided the original author and source are credited.

\section{ABSTRACT}

Chronic inflammation is one of the underlying risks associated with thyroid cancer. We ascertained the association between commonly measured serum biomarkers of inflammation and the risk of thyroid cancer in Swedish Apolipoproteinrelated MORtality RISk (AMORIS) study. 226,212 subjects had baseline measurements of C-reactive protein, albumin and haptoglobin. Leukocytes were measured in a subgroup of 63,845 subjects. Associations between quartiles and dichotomized values of inflammatory markers and risk of thyroid cancer were analysed using multivariate Cox proportional hazard models. 202 individuals were diagnosed with thyroid cancer during a mean follow-up of $\mathbf{1 9 . 6}$ years. There was a positive association between lower albumin levels and risk of developing thyroid cancer [Hazard Ratio for albumin $\leq \mathbf{4 0}$ g/L: $1.50(95 \%$ Confidence Interval $=1.04-2.16)]$. When stratified by a metabolic score, we observed similar association for albumin with higher HR among those with metabolic score $\geq 1$, as compared to those with metabolic score of 0 [HR 1.98 (95\% CI $=1.11-3.54)$ vs $1.17(95 \% C I=0.72-1.89)](P=0.19)$. Apart from albumin, none of the serum markers of inflammation studied showed a link with the risk of developing thyroid cancer-suggesting that the role of inflammation may be more complicated and requires assessment of more specialised measurements of inflammation.

\section{INTRODUCTION}

Thyroid cancer is the most common endocrine malignancy [1]. There has been an increase in its incidence in the Nordic countries, especially in Sweden between 1970 and 2013 [2]. Reactive oxygen species and proinflammatory cytokines generated in chronic inflammation are thought to initiate or promote cancer, and can affect disease progression [3]. For thyroid cancer, histological studies have confirmed the infiltration of white blood cell components such as CD8+ and CD4+ regulatory $\mathrm{T}$ lymphocytes in cancer tissues [4]. Moreover, increased levels of positive acute phase proteins like C-reactive protein (CRP), haptoglobin, galectin-3, IL6, 
G-CSF, sICAM-1, high neutrophil-to-lymphocyte ratio (NLR) and decreased levels of negative acute phase proteins like albumin, pre-albumin, and transferrin have been found in sera of patients with thyroid cancers [5-8]. Epidemiological studies have also suggested a link between chronic inflammation and risk factors for developing a thyroid cancer such as radiation exposure during childhood or as an occupational hazard [9], downstream genetic mechanisms in familial thyroid cancer syndromes [10], Hashimoto's Thyroiditis [11], obesity [12], Hepatitis C-related chronic hepatitis [13] and increased parity and lactation [14].

Nevertheless, there are only a few observational studies exploring the link between inflammation and the risk of developing a thyroid cancer using systemic inflammatory markers. A recent study based on the European Prospective Investigation into Cancer and Nutrition (EPIC) cohort showed that insulin-like growth factor-I concentrations may be positively associated with the risk of developing differentiated thyroid carcinoma [15]. In a case-control study with 114 cases of thyroid cancer and 333 matched controls from the Janus serum bank in Norway, a positive association between serum albumin levels and the risk of developing papillary carcinoma and follicular carcinoma of the thyroid was found [16].

This study aimed to further evaluate this association. We explored the risk of developing a thyroid cancer by assessing serum biomarkers that are commonly measured in clinical practice and are indicative of inflammation (CRP, albumin, haptoglobin and leukocytes) in a large Swedish cohort study [17].

\section{RESULTS}

Characteristics of study participants are shown in Table 1. During a mean follow-up of 19.6 years, 202 subjects developed thyroid cancer.

Lower values of serum albumin were associated with the risk of developing a thyroid cancer [HR for albumin $\leq 40 \mathrm{~g} / \mathrm{L}: 1.50(95 \% \mathrm{CI}=1.04-2.16)]$ in a multivariate model (Table 2). Additional adjustment for serum levels of triglycerides, glucose, and total cholesterol weakened the association slightly: HR 1.41 (95\% CI = 0.97-2.04). No associations were observed for CRP, haptoglobin, or leukocytes with the risk of developing a thyroid cancer.

When stratified by a proxy variable for obesity (metabolic score), we observed a similar positive association between albumin and the risk of developing a thyroid cancer in both groups, with a slightly higher HR for those with a metabolic score $\geq 1$ [HR $1.98(95 \%$ CI $=1.11-3.54)])$ vs those with a metabolic score of $0(1.17(95 \% \mathrm{CI}=0.72$ 1.89)]. However, there was no statistically significant interaction $(P=0.19)$ by metabolic score (Table 3$)$. No effect modification by sex was observed (results not shown).
We further modelled the potential association between serum albumin and the risk of developing a thyroid cancer through a dose-response curve with restrictive cubic splines (Figure 1). The direction of the hazard ratios observed was consistent with shape of the curve.

A sensitivity analysis was done to assess reverse causation by excluding those with follow-up $<3$ and $<$ 5 years. It did not affect the above findings (results not shown).

\section{DISCUSSION}

In the AMORIS study, we found evidence for an inverse association between serum albumin levels and the risk of developing a thyroid cancer. This inverse association became stronger when measured in a subgroup of subjects with serum triglycerides and total cholesterol above normal. No associations with the risk of developing a thyroid cancer were observed for CRP, haptoglobin, or leukocytes.

Molecular pathways linking inflammation and development of a thyroid cancer have been increasingly studied. For instance, increased expression of autotaxin, lysophosphatidate and inflammatory mediators has been found in malignant thyroid disease. It has been postulated that autotaxin is an integral component of tumorigenesis in thyroid follicular cells leading to tumour growth and promoting markers of more aggressive tumour phenotypes including proliferation, vascularity, metastasis, immune evasion, and treatment resistance $[18,19]$. Moreover, inflammation is thought to play a role in papillary carcinoma of the thyroid, which is characterized by the presence of chemokine-guided macrophage and dendritic cell infiltration [20-22]. However, the majority of the studies investigating serum biomarkers and thyroid carcinogenesis have focused on progression and treatment response, with little focus on the risks of developing thyroid cancer $[6,8,23]$.

The observed association between albumin and the risk of developing a thyroid cancer may support the wellestablished concept of low serum albumin as a marker of poor health status $[24,25]$. Our results are different from a Norwegian case control study [16] and did not find a link between risk of developing a thyroid cancer and serum levels of CRP, haptoglobin and leukocytes, which is consistent with the few studies previously investigating this association $[5,6,23]$.

This is to our knowledge the largest prospective study assessing common serum markers of inflammation with the risk of developing a thyroid cancer. The strength of this study lies in the prospective evaluation of exposures and complete follow-up of study participants through national health registers. All analyses were performed at CALAB using internationally accredited and calibrated methods [26]. The population in AMORIS is based on data 
Table 1: Descriptive statistics of the study population by thyroid cancer status

\begin{tabular}{|c|c|c|c|c|}
\hline & \multicolumn{2}{|c|}{ All $(n=226212)$} & \multicolumn{2}{|c|}{$\begin{array}{l}\text { Subgroup with additional measurement of leukocytes } \\
\qquad(n=63845)\end{array}$} \\
\hline & $\begin{array}{l}\text { Thyroid cancer } \\
\quad(n=202)\end{array}$ & $\begin{array}{l}\text { No thyroid cancer } \\
(n=226010)\end{array}$ & $\begin{array}{l}\text { Thyroid cancer } \\
\quad(n=66)\end{array}$ & $\begin{array}{l}\text { No thyroid cancer } \\
\quad(n=63779)\end{array}$ \\
\hline Mean age (yrs.) (SD) & $48.28(13.93)$ & $45.77(13.93)$ & $51.2(16.10)$ & $50.6(16.10)$ \\
\hline \multicolumn{5}{|l|}{ Gender } \\
\hline Male & $72(35.64)$ & $120409(53.28)$ & $17(25.76)$ & $27559(43.21)$ \\
\hline Female & $130(64.36)$ & 105601 (46.72) & $49(74.28)$ & $36220(56.79)$ \\
\hline \multicolumn{5}{|l|}{ Parity } \\
\hline Nulliparous & $22(10.89)$ & $32411(14.34)$ & $7(10.61)$ & $9135(14.32)$ \\
\hline $1+$ & $127(62.87)$ & $146996(65.04)$ & $40(60.61)$ & 34210 (53.64) \\
\hline Missing & $53(26.24)$ & $46603(20.62)$ & $19(28.79)$ & 20434 (32.04) \\
\hline \multicolumn{5}{|l|}{ Socio-economic status } \\
\hline White collar & $86(42.57)$ & $109373(48.39)$ & $23(34.85)$ & $28275(44.33)$ \\
\hline Blue collar & $95(47.03)$ & $97858(43.30)$ & $28(42.42)$ & $24999(39.20)$ \\
\hline Unemployed/missing & $21(10.40)$ & $18779(8.31)$ & $15(22.73)$ & $10505(16.47)$ \\
\hline \multicolumn{5}{|l|}{ Education } \\
\hline Low & $65(32.18)$ & $58892(26.06)$ & $18(27.27)$ & $15081(23.65)$ \\
\hline Middle & $92(45.54)$ & $97205(43.01)$ & $32(48.48)$ & $26081(40.89)$ \\
\hline High & $40(19.80)$ & $61025(27.00)$ & $14(21.21)$ & 17966 (28.17) \\
\hline Missing & $5(2.48)$ & $8888(3.93)$ & $2(3.03)$ & $4651(7.29)$ \\
\hline \multicolumn{5}{|c|}{ Charslon Comorbidity Index } \\
\hline 0 & $188(93.07)$ & 208707 (92.34) & $59(89.39)$ & $56540(88.65)$ \\
\hline 1 & $5(2.48)$ & $9107(4.03)$ & $3(4.55)$ & $3500(5.49)$ \\
\hline 2 & $9(4.46)$ & $6085(2.69)$ & $4(6.06)$ & $2677(4.20)$ \\
\hline $3+$ & $0(0.0)$ & $2111(0.93)$ & $0(0.0)$ & $1062(1.67)$ \\
\hline \multicolumn{5}{|c|}{ Body mass index $\left(\mathrm{kg} / \mathrm{m}^{2}\right)$} \\
\hline$<18.5$ & $1(0.49)$ & $829(0.37)$ & $0(0.0)$ & $200(0.31)$ \\
\hline $18.5-24.99$ & $20(9.90)$ & 27419 (12.13) & $4(6.06)$ & $3920(6.15)$ \\
\hline $25-29.99$ & $14(6.93)$ & $14909(6.59)$ & $1(1.51)$ & $1855(2.91)$ \\
\hline$>=30$ & $2(0.99)$ & $3623(1.60)$ & $0(0)$ & $491(0.77)$ \\
\hline Missing & $165(81.68)$ & $179230(79.30)$ & $61(92.42)$ & $57313(89.86)$ \\
\hline \multicolumn{5}{|l|}{ CRP (mg/L) } \\
\hline Mean (SD) & $506(3.0)$ & $5.57(3.0)$ & $5.35(4.0)$ & $5.59(3.0)$ \\
\hline$<10$ & $163(80.69)$ & $186574(82.55)$ & $54(81.82)$ & 52485 (82.29) \\
\hline$>=10$ & $39(19.31)$ & 39436 (17.45) & $12(18.18)$ & 11294 (17.71) \\
\hline \multicolumn{5}{|l|}{ Albumin $(\mathrm{g} / \mathrm{L})$} \\
\hline Mean (SD) & $42.30(42.0)$ & $42.73(43.0)$ & $42.74(43.0)$ & $42.45(42.0)$ \\
\hline$<40$ & 37 (18.32) & $26725(11.82)$ & $7(10.61)$ & $9356(14.67)$ \\
\hline$>=40$ & $165(81.68)$ & 199285 (88.18) & $59(89.39)$ & $54423(85.33)$ \\
\hline \multicolumn{5}{|l|}{ Haptoglobin (g/L) } \\
\hline Mean (SD) & $1.03(1.0)$ & $1.05(1.0)$ & $1.09(1.10)$ & $1.08(1.0)$ \\
\hline$<1.4$ & 174 (86.14) & 194747 (86.17) & $53(80.3)$ & $53816(84.38)$ \\
\hline$>=1.4$ & $28(13.86)$ & $31263(13.83)$ & 13 (19.7) & $9963(15.62)$ \\
\hline \multicolumn{5}{|l|}{ Leukocyte $(109 / \mathrm{L})^{*}$} \\
\hline Mean (SD) & & & $6.31(5.95)$ & $6.69(6.30)$ \\
\hline$<10$ & & & $63(95.45)$ & 59607 (93.46) \\
\hline$>=10$ & & & $3(4.55)$ & $4172(4.55)$ \\
\hline \multicolumn{5}{|l|}{ Fasting status } \\
\hline Fasting & $133(65.84)$ & $139561(61.75)$ & $35(53.03)$ & 37791 (59.25) \\
\hline Not fasting & $69(34.16)$ & 84441 (37.36) & $31(46.97)$ & $24625(38.61)$ \\
\hline
\end{tabular}




\begin{tabular}{lcccc} 
Missing & $0(0)$ & $2008(0.89)$ & 0 & $1363(2.14)$ \\
Glucose (mmol/L) & & & $5.07(1.46)$ \\
Mean (SD) & $4.9(0.96)$ & $4.9(1.28)$ & $4.89(0.68)$ & $57502(92.13)$ \\
$<6.11$ & $187(92.57)$ & $210508(93.14)$ & $63(95.45)$ & $4914(7.87)$ \\
$>=6.11$ & $15(7.43)$ & $13494(5.97)$ & 0 & $1363(2.14)$ \\
Missing & $0(0)$ & $2008(0.89)$ & $1.55)$ & $1.34(1.05)$ \\
Triglycerides (mmol/L) & & & $1.26(0.74)$ & $49362(77.4)$ \\
Mean (SD) & $1.5(2.1)$ & $1.31(1.0)$ & $53(80.3)$ & $13048(20.46)$ \\
$<1.71$ & $162(80.2)$ & $177854(78.69)$ & $13(19.7)$ & $1369(2.15)$ \\
$>=1.71$ & $40(19.8)$ & $46244(20.46)$ & 0 & $5.63(1.16)$ \\
Missing & $0(0)$ & $1912(0.85)$ & $5.52(0.99)$ & $48427(75.93)$ \\
Total cholesterol (mmol/L) & & & $52(78.79)$ & $13991(21.94)$ \\
Mean (SD) & $5.60(1.2)$ & $5.60(1.1)$ & $14(21.21)$ & $1361(2.13)$ \\
$<6.5$ & $158(78.22)$ & $177049(78.34)$ & 0 & \\
$>=6.5$ & $44(21.78)$ & $47060(20.82)$ & \\
Missing & $0(0.0)$ & $1901(0.84)$ & & \\
\hline
\end{tabular}

"Only measured in subgroup.

from health check-ups in non-hospitalized persons and people referred for blood sampling, and is representative of the general working population of Stockholm [27-28].

It is a limitation that high-sensitive CRP was not available at the time measurements were conducted. Any CRP levels $<10 \mathrm{mg} / \mathrm{L}$ were unquantifiable, which may have resulted in an underestimation of the association with risk of developing a thyroid cancer. Information on BMI was not available for a large proportion in the current subset of AMORIS participants, so we used a metabolic score as an obesity proxy. Another limitation is the lack of data on histological variants of thyroid cancer [29], as well as other potential confounders such as smoking habits, diet and iodine consumption, exposure to ionizing radiation, thyroid endocrine abnormalities [30] or other serum biomarkers of inflammation such as IL-6 or IL8. In addition, even though some studies have detected that overexpression of vascular endothelial growth factor C (VEGF-C) mRNA in thyroid cancer tissue has been associated with a high prevalence of lymph node metastasis, any such association could not be studied in the current AMORIS study due to lack of information on VEGF-C [31-35].

\section{MATERIALS AND METHODS}

\section{Study population and data collection}

The Swedish Apolipoprotein-related MORtality RISk data-base (AMORIS) includes blood samples from 812,073 Swedish men and women, ranging in age from $<20$ to 80 years old and over undergoing occupational health screening or primary care. The cohort is based on a linkage between data from laboratory examinations performed in the Central Automation Laboratory (CALAB) in Sweden and information recorded in Swedish National Registers using a 10-digit personal identifier number, which is unique to every Swedish resident. AMORIS is a large prospective cohort with information on serum biomarkers, cancer diagnosis, co-morbidities, vital status, socioeconomic status, and emigration. This study complied with the Declaration of Helsinki and was approved by the Ethics Review Board of the Karolinska Institute.

We restricted our study population to individuals aged 20 years or older who did not have a previous diagnosis of cancer. Furthermore, all subjects were required to have baseline measurements of CRP, albumin, and haptoglobin available from the same health examination $(n=226,212)$. Leukocytes were measured for a subgroup of the study population $(n=63,845)$. The choice of biomarkers was guided by recommendations from similar studies done using data from the AMORIS study [36-38]. The outcome investigated in this study was development of a thyroid cancer (International Classification of Diseases, Revision 7 (1955) code 194) [39].

Serum CRP $(\mathrm{mg} / \mathrm{L})$, albumin $(\mathrm{g} / \mathrm{L})$, haptoglobin $(\mathrm{g} / \mathrm{L})$, leukocytes $(10 \times 109 / \mathrm{L})$, triglycerides $(\mathrm{mmol} / \mathrm{L})$, total cholesterol $(\mathrm{mmol} / \mathrm{L})$ and glucose $(\mathrm{mmol} / \mathrm{L})$ were measured at baseline with standard laboratory methods as described elsewhere [40]. High sensitive CRP (hsCRP) was not available at any time in the period of blood sample collection (1985-1996), so CRP concentrations < $10 \mathrm{mg} / \mathrm{L}$ could not be measured precisely [26]. However, the cut-off point of $10 \mathrm{mg} / \mathrm{L}$ is widely accepted as the upper limit of the health-associated reference range and was therefore used in this study [41]. Levels of serum inflammatory markers were assessed as high or low based on their clinical cut-offs as used in CALAB: CRP $10 \mathrm{mg} / \mathrm{L}$, haptoglobin $1.4 \mathrm{~g} / \mathrm{L}$ and leukocytes $10 \times 109 / \mathrm{L}$. For albumin, a cut-off point of $40 \mathrm{~g} / \mathrm{L}$ was used instead of $35 \mathrm{~g} / \mathrm{L}$ due to the small number of participants with low albumin levels. 
Serum glucose, total cholesterol, and triglycerides levels were dichotomised using clinical cut-offs in accordance with the American Diabetes Association and National Cholesterol Education Programme (NCEP) guidelines (cut-offs: 6.11, 6.50, and 1.71 $\mathrm{mmol} / \mathrm{L}$ for glucose, total cholesterol, and triglycerides respectively) [42]. Obesity is linked to inflammation and development of a thyroid cancer [43-46], but limited information on body mass index (BMI) was available for this group of participants in AMORIS. Hence, we created a proxy variable (metabolic score) based on the sum of these three dichotomous variables indicating whether triglyceride, glucose, and total cholesterol were above their clinical cut-offs [37, 47]. In addition, the following baseline information was obtained from AMORIS: parity (nulliparous, $1+$ children), educational level (low, intermediate,

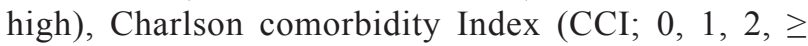
3 ), and fasting status (fasting, non-fasting, missing). Follow-up time was defined as the time from baseline measurements until date of cancer diagnosis, date of death, emigration, or end of study (31st December 2011), whichever came first.

\section{Data analyses}

We estimated the risk of developing a thyroid cancer with multivariate Cox proportional hazards regression, comparing people with high to low levels of CRP, albumin, haptoglobin and leukocytes respectively. Cox regression models were adjusted for age, sex, education, and CCI, as well as triglycerides (continuous), glucose (continuous), total cholesterol (continuous), and fasting status. The assumption of proportional hazards was evaluated by adding time dependent covariates into the models as well as by assessment of the Schoenfeld Residuals.

We performed stratified analyses based on the values of the above-described metabolic score $(0 \mathrm{vs} \geq 1)$ to evaluate effect modification by metabolic abnormalities. In addition, stratification by sex was performed.

Based on current evidence, the World Trade Center Program Administrator under Centers for Disease Control and Prevention (CDC) sets the minimum latency for developing a thyroid cancer as 2.5 years, which is well covered within our follow up time [48]. Nevertheless, we assessed reverse causality through two sensitivity analyses

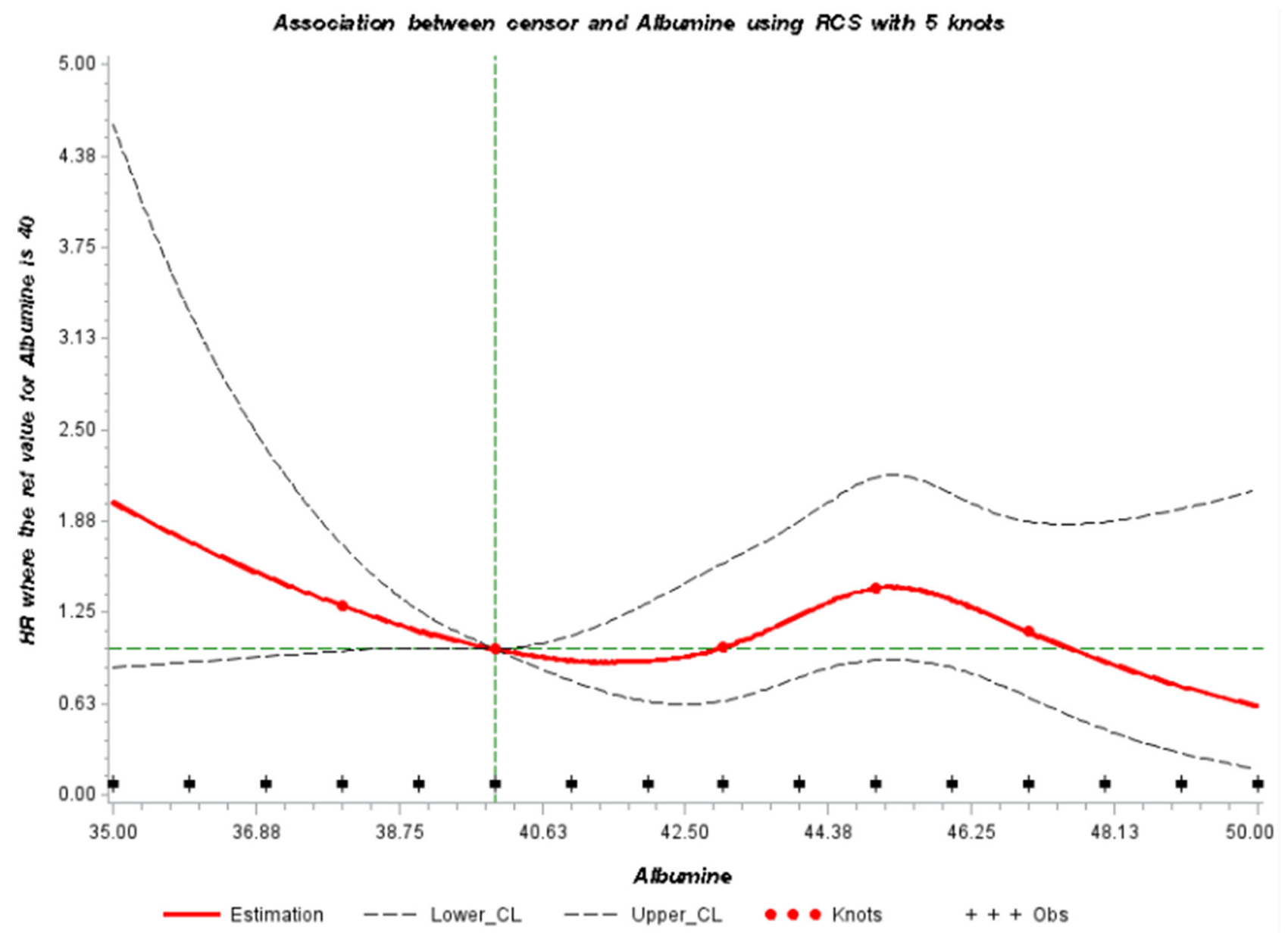

Figure 1: Adjusted dose-response association between serum levels of albumin (in $\mathrm{g} / \mathrm{L}$ ) and risk of thyroid cancer using restrictive cubic splines. HR: Hazard ratio, RCS: restrictive cubic splines. 
Table 2: Hazard ratio (HR) for risk of thyroid cancer with $95 \%$ confidence intervals (CI) using Cox proportional hazards model

\begin{tabular}{|c|c|c|c|}
\hline & $\begin{array}{c}\text { Crude } \\
\text { HR }(95 \% \text { CI })\end{array}$ & $\begin{array}{c}\text { Adjusted }^{1} \\
\text { HR }(95 \% \text { CI) }\end{array}$ & $\begin{array}{c}\text { Adjusted }{ }^{2} \\
\text { HR }(95 \% \text { CI) }\end{array}$ \\
\hline \multicolumn{4}{|c|}{ CRP (mg/L) } \\
\hline$>=10$ & $1.06(0.75-1.51)$ & $1.02(0.72-1.46)$ & $1.00(0.70-1.43)$ \\
\hline \multicolumn{4}{|c|}{ Albumin (g/L) } \\
\hline$<=40$ & $1.88(1.31-2.68)$ & $1.50(1.04-2.16)$ & $1.41(0.97-2.04)$ \\
\hline \multicolumn{4}{|c|}{ Haptoglobin (g/L) } \\
\hline$>=1.4$ & $1.09(0.74-1.64)$ & $1.02(0.69-1.53)$ & $0.99(0.67-1.49)$ \\
\hline \multicolumn{4}{|c|}{ Leukocytes $\left(10^{9} / \mathbf{L}\right)^{*}$} \\
\hline$>=10$ & $0.75(0.23-2.38)$ & $0.75(0.23-2.39)$ & $0.73(0.23-2.32)$ \\
\hline
\end{tabular}

${ }^{1}$ adjusted for age, sex, education, Charslon Comorbidity Index

${ }^{2}$ adjusted for age, sex, education, Charslon Comorbidity Index, triglyceride (continuous), glucose (continuous), total cholesterol (continuous), fasting status

*In subgroup with additional measurement for leukocytes $n=63,845$.

Table 3: Hazard ratio (HR) for risk of thyroid cancer with $95 \%$ confidence intervals (CI) using Cox proportional hazards model stratified by metabolic score

\begin{tabular}{|c|c|c|c|}
\hline & $\begin{array}{c}\text { Metabolic score }=0 \\
\text { HR }(95 \% \text { CI })\end{array}$ & $\begin{array}{c}\text { Metabolic score } \geq 1 \\
\text { HR }(95 \% \text { CI })\end{array}$ & $\mathbf{P}_{\text {Interaction }}$ \\
\hline \multicolumn{4}{|c|}{ CRP (mg/L) } \\
\hline$>=10$ & $1.10(0.72-1.69)$ & $0.82(0.43-1.56)$ & 0.37 \\
\hline \multicolumn{4}{|c|}{ Albumin (g/L) } \\
\hline$<=40$ & $1.17(0.72-1.89)$ & $1.98(1.11-3.54)$ & 0.19 \\
\hline \multicolumn{4}{|c|}{ Haptoglobin (g/L) } \\
\hline$>=1.4$ & $0.94(0.54-1.66)$ & $1.08(0.59-1.94)$ & 0.73 \\
\hline \multicolumn{4}{|c|}{ Leukocytes $\left(10^{9} / \mathrm{L}\right)^{*}$} \\
\hline$>=10$ & $0.42(0.06-3.09)$ & $1.13(0.26-4.90)$ & 0.45 \\
\hline
\end{tabular}

* In subgroup with 63,845 measurements

All models were adjusted for age, sex, education, Charslon Comorbidity Index, triglyceride (continuous), glucose (continuous), total cholesterol (continuous), and fasting status.

excluding those with follow-up time $<3$ years and $<5$ years, respectively.

For those biomarkers in which we observed an association based on the hazard ratios, we used the Restrictive Cubic Spline (RCS) function to graphically display the hazard ratios representing the dose-response association. We used knots located at the 5th, 25th, 75th and 95th percentiles as well as the medical reference value [49] in a multivariate Cox proportional hazards model as described above. This analysis was performed using the RCS_Reg SAS Macro created by Desquilbet and Mariotti [50].

All analyses were conducted with Statistical Analysis Systems (SAS) software release 9.4 (SAS Institute, Cary, NC) [51].

\section{CONCLUSIONS}

The observation of an association between low levels of albumin and the risk of developing a thyroid cancer suggests the importance of inflammation as one of the mechanisms underlying carcinogenic development. The lack of an association with other commonly measured markers of inflammation indicates that the role of inflammation in the development of a thyroid cancer may be more complicated and would require more detailed data on markers of inflammation such as interleukins or gamma-delta T-cells. Future studies should entail temporality of associations between inflammation and development of thyroid cancers to further identify their clinical or public health importance. 


\section{Abbreviations}

AMORIS: Apolipoprotein-related MORtality RISk; CALAB: Central Automation Laboratory; CCI: Charlson Comorbidity Index; CDC: Centers for Disease Control and Prevention; CI: Confidence interval; CRP: C-reactive protein; EPIC: European Prospective Investigation into Cancer and Nutrition; g/L: gram per litre; G-CSF: Granulocyte-colony stimulating factor; HR: Hazard ratio; hsCRP: High sensitive CRP; IL6: Interleukin 6; IL8: Interleukin 8; mg/dl: milligram per decilitre; $\mathrm{Mmol} / \mathrm{L}$ : millimoles per litre; NCEP: National Cholesterol Education Programme; NLR: neutrophil-to-lymphocyte ratio; RCS: restricted cubic splines; SAS: Statistical Analysis System; SD: Standard deviation; sICAM-1: serum Intercellular Adhesion Molecule 1; VEGF-C: vascular endothelial growth factor $\mathrm{C}$.

\section{Author contributions}

A.G. was involved in project development, data analysis, and manuscript writing. H.G. was involved in project development, data analysis, and manuscript editing. R.A. was involved in data analysis, and manuscript editing. P.C., L.H., N.H., I.J., H.M., M.L., and G.W. were involved in data collection, and manuscript editing. M.V.H. was involved in project development, and manuscript editing.

\section{ACKNOWLEDGMENTS}

The Swedish Cancer Society; Gunnar and Ingmar Jungner Foundation for Laboratory Medicine, Stockholm, Sweden; National Institute for Health Research (NIHR) Biomedical Research Centre based at Guy's and St Thomas' NHS Foundation Trust and King's College London; and Ms. Rosemary Drescher for proof reading.

\section{CONFLICTS OF INTEREST}

None to declare.

\section{FUNDING}

The research was funded/supported by the Swedish Cancer Society; grants from the Gunnar and Ingmar Jungner Foundation for Laboratory Medicine, Stockholm, Sweden; and the National Institute for Health Research (NIHR) Biomedical Research Centre based at Guy's and St Thomas' NHS Foundation Trust and King's College London. The views expressed are those of the author(s) and not necessarily those of the Cancerfonden, NHS, the NIHR or the Department of Health.

\section{REFERENCES}

1. Nguyen QT, Lee EJ, Huang MG, Park YI, Khullar A, Plodkowski RA. Diagnosis and treatment of patients with thyroid cancer. Am Health Drug Benefits. 2015; 8:30-40.

2. Carlberg M, Hedendahl L, Ahonen M, Koppel T, Hardell L. Increasing incidence of thyroid cancer in the Nordic countries with main focus on Swedish data. BMC Cancer. 2016; 16:426. https://doi.org/10.1186/s12885-016-2429-4.

3. Hanahan D, Weinberg RA. Hallmarks of Cancer: The Next Generation. Cell. 2011; 144:646-74. https://doi. org/10.1016/j.cell.2011.02.013.

4. Ward LS. Immune response in thyroid cancer: widening the boundaries. Scientifica (Cairo). 2014; 2014:125450. https:// doi.org/10.1155/2014/125450.

5. Czarnywojtek A, Owecki M, Zgorzalewicz-Stachowiak M, Woliński K, Szczepanek-Parulska E, Budny B, Florek E, Waligórska-Stachura J, Miechowicz I, Bączyk M, Sawicka N, Dhir S, Ruchała M. The role of serum C-reactive protein measured by high-sensitive method in thyroid disease. Arch Immunol Ther Exp (Warsz). 2014; 62:501-9. https://doi. org/10.1007/s00005-014-0282-1.

6. Hou X, Jiang L, Chen C, Zhu X, Ge M. Different Expression of Erythrocyte Sedimentation Rate and C-reactive Protein in Papillary Thyroid Carcinoma and Nodular Goiter. Clin Lab. 2015; 61:793-99. https://doi.org/10.7754/Clin. Lab.2015.150127.

7. Provatopoulou X, Georgiadou D, Sergentanis TN, Kalogera E, Spyridakis J, Gounaris A, Zografos GN. Interleukins as markers of inflammation in malignant and benign thyroid disease. Inflamm Res. 2014; 63:667-74.

8. Shimura T, Shibata M, Gonda K, Nakajima T, Chida S, Noda M, Suzuki S, Nakamura I, Nakano K, Fukushima T, Suzuki S, Takenoshita S. Circulating galectin-3 correlates with angiogenetic factors, indicators of nutritional condition and systemic inflammation in patients with thyroid cancer. Ann Cancer Res. 2016; 24:35.40.

9. Schneider AB, Sarne DH. Long-term risks for thyroid cancer and other neoplasms after exposure to radiation. Nat Clin Pract Endocrinol Metab. 2005; 1:82-91. https://doi. org/10.1038/ncpendmet0022.

10. Hemminki K, Eng C, Chen B. Familial risks for nonmedullary thyroid cancer. J Clin Endocrinol Metab. 2005; 90:5747-53. https://doi.org/10.1210/jc.2005-0935.

11. Lai X, Xia Y, Zhang B, Li J, Jiang Y. A meta-analysis of Hashimoto's thyroiditis and papillary thyroid carcinoma risk. Oncotarget. 2017; 8:62414-24. https://doi. org/10.18632/oncotarget.18620.

12. Kitahara CM, McCullough ML, Franceschi S, Rinaldi S, Wolk A, Neta G, Olov Adami H, Anderson K, Andreotti G, Beane Freeman LE, Bernstein L, Buring JE, ClavelChapelon F, et al. Anthropometric Factors and Thyroid Cancer Risk by Histological Subtype: Pooled Analysis of 22 Prospective Studies. Thyroid. 2016; 26:306-18. https:// doi.org/10.1089/thy.2015.0319. 
13. Antonelli A, Ferri C, Fallahi P, Pampana A, Ferrari SM, Barani L, Marchi S, Ferrannini E. Thyroid cancer in HCV-related chronic hepatitis patients: a case-control study. Thyroid. 2007; 17:447-51. https://doi.org/10.1089/ thy.2006.0194.

14. Rossing MA, Voigt LF, Wicklund KG, Daling JR. Reproductive factors and risk of papillary thyroid cancer in women. Am J Epidemiol. 2000; 151:765-72. https://doi. org/10.1093/oxfordjournals.aje.a010276.

15. Schmidt JA, Allen NE, Almquist M, Franceschi S, Rinaldi S, Tipper SJ, Tsilidis KK, Weiderpass E, Overvad K, Tjønneland A, Boutron-Ruault MC, Dossus L, Mesrine S, et al. Insulin-like growth factor-i and risk of differentiated thyroid carcinoma in the European prospective investigation into cancer and nutrition. Cancer Epidemiol Biomarkers Prev. 2014; 23:976-85. https://doi.org/10.1158/1055-9965. EPI-13-1210-T.

16. Glattre E, Engeland A, Høstmark AT, Jellum E. Serumalbumin and risk of thyroid cancer: A population-based, matched case-control study,. Nor Epidemiol. 2009; 11.

17. Walldius G, Malmström H, Jungner I, de Faire U, Lambe M, Van Hemelrijck M, Hammar N. Cohort Profile: The AMORIS cohort. Article Navigation Cohort Profile: The AMORIS cohort. International Journal of Epidemiology. 2017; 46:1103-1103i. https://doi.org/10.1093/ije/dyw333.

18. Benesch MGK, Ko YM, McMullen TPW, Brindley DN. Autotaxin in the crosshairs: Taking aim at cancer and other inflammatory conditions. FEBS Lett. 2014; 588:2712-27. https://doi.org/10.1016/j.febslet.2014.02.009.

19. Benesch MGK, Ko YM, Tang X, Dewald J, LopezCampistrous A, Zhao YY, Lai R, Curtis JM, Brindley DN, McMullen TPW. Autotaxin is an inflammatory mediator and therapeutic target in thyroid cancer. Endocr Relat Cancer. 2015; 22:593-607. https://doi.org/10.1530/ERC-15-0045.

20. Russell JP, Shinohara S, Melillo RM, Castellone MD, Santoro M, Rothstein JL. Tyrosine kinase oncoprotein, RET/PTC3, induces the secretion of myeloid growth and chemotactic factors. Oncogene. 2003; 22:4569-77. https:// doi.org/10.1038/sj.onc. 1206759.

21. Russell JP, Engiles JB, Rothstein JL. Proinflammatory mediators and genetic background in oncogene mediated tumor progression. J Immunol. 2004; 172:4059-67. https:// doi.org/10.4049/jimmunol.172.7.4059.

22. Borrello MG, Alberti L, Fischer A, Degl'Innocenti D, Ferrario C, Gariboldi M, Marchesi F, Allavena P, Greco A, Collini P, Pilotti S, Cassinelli G, Bressan P, et al. Induction of a proinflammatory program in normal human thyrocytes by the RET/PTC1 oncogene. Proc Natl Acad Sci. 2005; 102:14825-30. https://doi.org/10.1073/pnas.0503039102.

23. Pearce EN, Bogazzi F, Martino E, Brogioni S, Pardini E, Pellegrini G, Parkes AB, Lazarus JH, Pinchera A, Braverman LE. The Prevalence of Elevated Serum C-Reactive Protein Levels in Inflammatory and Noninflammatory Thyroid Disease. Thyroid. 2003; 13:6438. https://doi.org/10.1089/105072503322239989.
24. Nicholson JP, Wolmarans MR, Park GR. The role of albumin in critical illness. Br J Anaesth. 2000; 85:599-610. https://doi.org/10.1093/bja/85.4.599.

25. Gupta D, Lis CG. Pretreatment serum albumin as a predictor of cancer survival: a systematic review of the epidemiological literature. Nutr J. 2010; 9:69. https://doi. org/10.1186/1475-2891-9-69.

26. Holme I, Aastveit AH, Hammar N, Jungner I, Walldius G. Inflammatory markers, lipoprotein components and risk of major cardiovascular events in 65,005 men and women in the Apolipoprotein MOrtality RISk study (AMORIS). Atherosclerosis. 2010; 213:299-305. https:// doi.org/10.1016/j.atherosclerosis.2010.08.049.

27. Wulaningsih W, Michaelsson K, Garmo H, Hammar N, Jungner I, Walldius G, Lambe M, Holmberg L, Van Hemelrijck M. Serum calcium and risk of gastrointestinal cancer in the Swedish AMORIS study. BMC Public Health. 2013; 13:663. https://doi.org/10.1186/1471-2458-13-663.

28. Statistics Sweden | SCB. Available from http://www.scb.se/ en_/\#.

29. Fugazzola L, Colombo C, Perrino M, Muzza M. Papillary thyroid carcinoma and inflammation. Front Endocrin. 2011; 2:88. https://doi.org/10.3389/fendo.2011.00088.

30. Repplinger D, Bargren A, Zhang YW, Adler JT, Haymart M, Chen H. Is Hashimoto's thyroiditis a risk factor for papillary thyroid cancer? J Surg Res. 2008; 150:49-52. https://doi.org/10.1016/j.jss.2007.09.020.

31. Yu XM, Lo CY, Chan WF, Lam KY, Leung P, Luk JM. Increased expression of vascular endothelial growth factor $\mathrm{C}$ in papillary thyroid carcinoma correlates with cervical lymph node metastases. Clin Cancer Res. 2005; 11:8063-9. https://doi.org/10.1158/1078-0432.CCR-05-0646.

32. Hung CJ, Ginzinger DG, Zarnegar R, Kanauchi H, Wong MG, Kebebew E, Clark OH, Duh QY. Expression of vascular endothelial growth factor-C in benign and malignant thyroid tumors. J Clin Endocrinol Metab. 2003; 88:3694-9. https://doi.org/10.1210/jc.2003-030080.

33. Bunone G, Vigneri P, Mariani L, Butó S, Collini P, Pilotti S, Pierotti MA, Bongarzone I. Expression of angiogenesis stimulators and inhibitors in human thyroid tumors and correlation with clinical pathological features. Am J Pathol. 1999; 155:1967-76. http://dx.doi.org/10.1016/S00029440(10)65515-0.

34. Fellmer PT, Sato K, Tanaka R, Okamoto T, Kato Y, Kobayashi M, Shibuya M, Obara T. Vascular endothelial growth factor-C gene expression in papillary and follicular thyroid carcinomas. Surgery. 1999; 126:1056-61. https:// doi.org/10.1067/msy.2099.101432.

35. Shushanov S, Bronstein M, Adélaïde J, Jussila L, Tchipysheva T, Jacquemier J, Stavrovskaya A, Birnbaum D, Karamyshkva A. VEGFc and VEGFR3 expression in human thyroid pathologies. Int J Cancer. 2000; 86:47-52. https://doi.org/10.1002/(SICI)10970215(20000401)86:1<47::AID-IJC7>3.0.CO;2-R.

36. Van Hemelrijck M, Holmberg L, Garmo H, Hammar N, Walldius G, Binda E, Lambe M, Jungner I. Association 
between levels of C-reactive protein and leukocytes and cancer: Three repeated measurements in the Swedish AMORIS study. Cancer Epidemiol Biomarkers Prev. 2011; 20:428-37. https://doi.org/10.1158/1055-9965.EPI-10-1190.

37. Van Hemelrijck M, Harari D, Garmo H, Hammar N, Walldius G, Lambe M, Jungner I, Holmberg L. Biomarkerbased score to predict mortality in persons aged 50 years and older: a new approach in the Swedish AMORIS study. Int J Mol Epidemiol Genet. 2012; 3:66-76.

38. Bosco C, Wulaningsih W, Melvin J, Santaolalla A, De Piano M, Arthur R, Van Hemelrijck M. Metabolic serum biomarkers for the prediction of cancer: a followup of the studies conducted in the Swedish AMORIS study. Ecancermedicalscience. 2015; 9:555. https://doi. org/10.3332/ecancer.2015.555.

39. International Classification of Diseases, Revision 7 (1955). Available 2017 Feb 10, from http://www.wolfbane.com/icd/ icd $7 \mathrm{~h} . \mathrm{htm}$.

40. Holme I, Aastveit AH, Jungner I, Walldius G. Relationships between lipoprotein components and risk of myocardial infarction: Age, gender and short versus longer followup periods in the Apolipoprotein MOrtality RISk study (AMORIS). J Intern Med. 2008; 264:30-38. https://doi. org/10.1111/j.1365-2796.2008.01925.x.

41. Wilkins J, Gallimore JR, Moore EG, Pepys MB. Rapid automated high sensitivity enzyme immunoassay of C-reactive protein. Clin Chem. 1998; 44:1358-61.

42. Expert Panel on Detection, Evaluation, and Treatment of High Blood Cholesterol in Adults. Executive Summary of The Third Report of The National Cholesterol Education Program (NCEP) Expert Panel on Detection, Evaluation, And Treatment of High Blood Cholesterol In Adults (Adult Treatment Panel III). JAMA. 2001; 285:2486-97. https:// doi.org/10.1001/jama.285.19.2486.
43. Han JM, Kim TY, Jeon MJ, Yim JH, Kim WG, Song DE, Hong SJ, Bae SJ, Kim HK, Shin MH, Shong YK, Kim WB. Obesity is a risk factor for thyroid cancer in a large, ultrasonographically screened population. Eur J Endocrinol. 2013; 168:879-86. https://doi.org/10.1530/EJE-13-0065.

44. Harari A, Endo B, Nishimoto S, Ituarte PH, Yeh MW. Risk of advanced papillary thyroid cancer in obese patients. Arch Surg. 2012; 147:805-11. https://doi.org/10.1001/ archsurg.2012.713.

45. Zhao ZG, Guo XG, Ba CX, Wang W, Yang YY, Wang J, Cao HY. Overweight, obesity and thyroid cancer risk: a metaanalysis of cohort studies. J Int Med Res. 2012; 40:204150. https://doi.org/10.1177/030006051204000601.

46. Marcello MA, Cunha LL, Batista FA, Ward LS. Obesity and thyroid cancer. Endocr Relat Cancer. 2014; 21:T255-71. https://doi.org/10.1530/ERC-14-0070.

47. McMillan DC. An inflammation-based prognostic score and its role in the nutrition-based management of patients with cancer. Proc Nutr Soc. 2008; 67:257-62. https://doi. org/10.1017/S0029665108007131.

48. Howard J. Minimum Latency \& Types or Categories of Cancer. World Trade Center Health Program. 2015; 2013:1-12.

49. Harrell FE Jr. Cox Proportional Hazards Regression Model. Regression Modeling Strategies. Springer Series in Statistics. 2001; 465-507. https://doi.org/10. 1007/978-14757-3462-1_19.

50. Desquilbet L, Mariotti F. Dose-response analyses using restricted cubic spline functions in public health research. Stat Med. 2010; 29:1037-57. https://doi.org/10.1002/ $\operatorname{sim} .3841$.

51. Statistical Analysis Software, SAS/STAT | SAS UK. Available 2016 Dec 31, from http://www.sas.com/en_gb/ software/analytics/stat.html. 